\title{
A Techno-Economic Comparison between PV and PVT Integrated Ground Source Heat Pumps for Multi-Family Houses
}

\author{
Nelson Sommerfeldt and Hatef Madani \\ KTH Royal Institute of Technology, Stockholm, Sweden
}

\begin{abstract}
As the demand for sustainable energy technologies grows, solar photovoltaics (PV) and heat pumps are increasingly being used in buildings. Hybrid PV-thermal (PVT) collectors have been researched for decades, but have not yet had success in the market. This study combines PVT and ground source heat pumps (GSHP) in a series connection for a multi-family house, and compares the technical and economic performance to GSHP and PV+GSHP systems. A complete systems model in TRNSYS is used for the solar heat pump system, and climate and economic boundary conditions come from the Swedish market. The results show that reducing the borehole length and/or spacing with no or a limited loss of efficiency is the greatest benefit of adding PVT, however a fully sized borehole field with PV is found to be the lowest cost design option. In systems with poor efficiency and high auxiliary boiler use, the addition of PVT can be the lowest cost option but is not preferable to the PV+GSHP when space is not a limitation. The reduction in borehole field area for a given heat pump efficiency is notable since many multi-family homes cannot install GSHP due to a lack of drilling space. PVT+GSHP systems could offer a new, low-carbon heating alternative for buildings previously outside of the heat pump market.
\end{abstract}

Keywords: Solar heat pump, solar hybrid, systems analysis, green buildings, energy efficiency, TRNSYS

\section{Introduction}

Integrating solar collectors into heat pump systems presents an opportunity for increased renewable energy fractions in buildings. There are two main strategies: solar thermal (ST) and photovoltaic (PV). With ST, the collectors are a secondary heat source that can either supply hot water directly, relieving the heat pump, or act as a supplemental heat source. With PV, renewable electricity directly powers the compressor for a portion of its operation. Most research has focused on the many forms of ST based systems however, the popularity of PV in Europe has led to a growth in interest in PV and PV-thermal (PVT) hybrid assisted heat pumps.

In northern Europe, a barrier to high solar fractions is the strong negative correlation between solar supply and space heating demand. Boreholes provide one option for seasonal thermal storage and large buildings with ground source heat pumps (GSHP) often have a borehole field that is more suitable than the single borehole often found in single family houses. The most common borehole storage applications use ST collectors (Rad and Fung, 2016) and can be combined with or without heat pumps depending on the mean store temperature, borehole geometry, and solar collector design (Chapuis and Bernier, 2009).

There are an increasing number of PVT+GSHP systems being constructed with borehole regeneration in Europe, but there are relatively few published simulation studies as compared to solar thermal systems. To help build this knowledge base, a PVT+GSHP system is analyzed in a Swedish climate, where the PVT collectors are connected in series between the boreholes and heat pump. This design has the benefit of keeping average collector temperatures low, simplifies system integration, and gives the collectors a direct connection to the borehole storage (Sommerfeldt and Madani, 2016).

Within emerging technologies, publically published economic results are particularly difficult to find. Series connected systems have been shown to reduce electricity demand, but may not be enough to justify the cost of the PVT array (Haller and Frank, 2011). The PVT can also reduce the necessary borehole length resulting in drilling cost savings (Bertram et al., 2012; Kjellsson et al., 2010; Reda, 2015), but how this compares with the marginal cost of PVT is less understood. This paper presents a techno-economic comparison of a solar GSHP system combined with $\mathrm{PV}$ and series connected PVT with the goal of identifying the net marginal gain of adding a thermal connection between the solar and heat pump systems. 


\section{Methodology}

The focus of this study is a multi-family house located in Stockholm, Sweden with 30 apartments, average energy consumption, and a high potential for solar energy (i.e. south facing roof with no shading). A baseline GSHP system is designed and tested with PV and series connected PVT arrays using TRNSYS17 (Klein et al., 2009). A parametric analysis is made considering reduced borehole field sizes to capture savings in drilling cost, and reduced solar array area to represent buildings with less ideal conditions for solar energy. The key performance indicators (KPI) used for comparison are seasonal performance factor (SPF) and total lifecycle cost (TLCC). Due to a lack of available empirical data of an equivalent system, this study is limited as a theoretical exploration. However, the heat pump system model has been checked against like systems and the PVT model is confirmed in a separate study.

\subsection{System and Model Descriptions}

A conceptual diagram of the series connected PVT+GSHP system is given in Fig. 1, which includes the notation for energy flows that are described in Tab. 1. The PV+GSHP system simply removes the thermal connection between the solar array and borehole circuit. A simplified version of the TRNSYS model is given in Fig. 2 where most of the outputs and controls are removed for clarity. Simulations are run with a three-minute time step for 20 years.

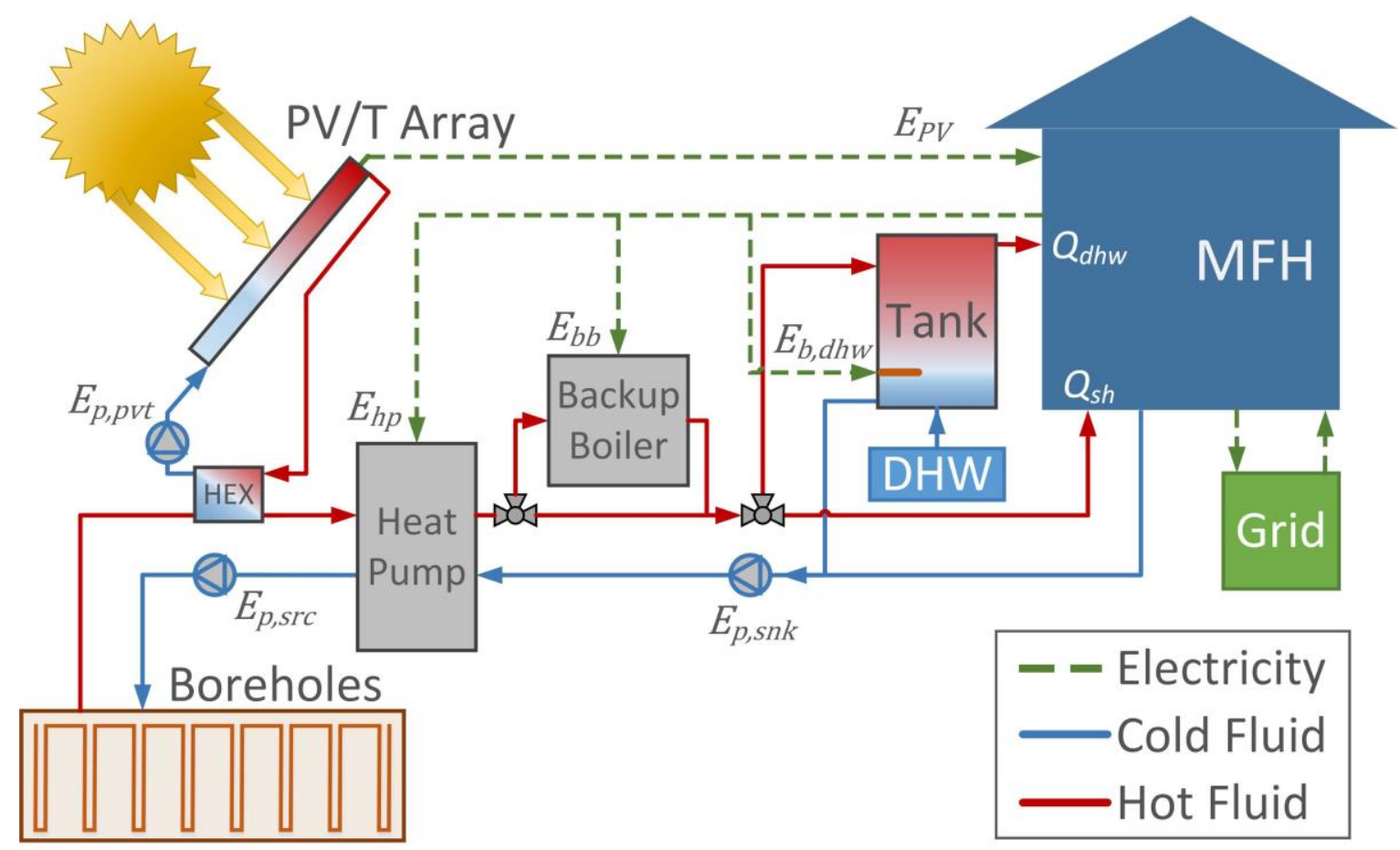

Fig. 1: Conceptual diagram of the PVT+GSHP system

Tab. 1: Technical nomenclature

\begin{tabular}{cc}
\hline Symbol & Quantity \\
\hline$Q_{s h}$ & Delivered thermal energy to space heating \\
$Q_{d h w}$ & Delivered thermal energy to domestic hot water \\
$E_{h p}$ & Electric energy to heat pump compressor \\
$E_{p, s r c}$ & Electric energy to borehole circuit (source) pump \\
$E_{p, s n k}$ & Electric energy to heat delivery (sink) pump \\
$E_{b b}$ & Electric energy to backup boiler \\
$E_{b, d h w}$ & Electric energy to backup elements in DHW tanks \\
$E_{p, p v t}$ & Electric energy to PVT circuit pump \\
$E_{P V}$ & Electric generation from PV array \\
$E_{a p t}$ & Electric plug loads in the apartments \\
$E_{H P}$ & Electric demand for entire HVAC system \\
$E_{p c, s c}$ & PV generation used by the heat pump (self-consumed) \\
$E_{p v, o p}$ & PV generation sold to the grid \\
\hline
\end{tabular}






Fig. 2: TRNSYS model representing the PVT+GSHP system

The climate data is based on a typical metrological year for Stockholm and generated using Meteonorm 7.2 (Remund and Kunz, 2018). The solar irradiation is based on the same dataset but has one-minute time steps synthetically generated using the Hofmann model (Hofmann et al., 2014) and averaged across the three-minute time step.

The building characteristics are from a typical Swedish multi-family house constructed between 1985 and 2005 (Spets, 2012), modeled using Type 56. Total conditioned area is $2000 \mathrm{~m}^{2}$ split across four floors and modeled with eight zones, where heating is delivered by wall mounted radiators (Type 1231). Domestic hot water is stored in two 1000 liter fully mixed tanks (Type 60) at $55^{\circ} \mathrm{C}$ and delivered at $50{ }^{\circ} \mathrm{C}$. DHW and apartment electricity usage is stochastically generated in one-minute time steps and averaged across the three-minute time step (Widén et al., 2009; Widén and Wäckelgård, 2010). Space heating demand is $125 \mathrm{kWh} / \mathrm{m}^{2}-\mathrm{yr}$, DHW demand is $38 \mathrm{kWh} / \mathrm{m}^{2}$-yr, and each apartment uses $2000 \mathrm{kWh}$ per year of electricity equivalent to $30 \mathrm{kWh} / \mathrm{m}^{2}$-yr. The roof has a gross area of $266 \mathrm{~m}^{2}$, faces directly south with a $20^{\circ}$ tilt, and is absent of shading or objects. Considering setbacks and collector geometry, the maximum array size is 144 collectors totaling $236 \mathrm{~m}^{2}$ and $40.3 \mathrm{~kW}_{\mathrm{p}}$.

The heat pump has a variable speed compressor with a nominal heating capacity of $52 \mathrm{~kW}$ (B0/W35) at $3600 \mathrm{RPM}$ and a power range of 21 to $88 \mathrm{~kW}$ corresponding to $1500-6000 \mathrm{RPM}$. The nominal coefficient of performance is 5.30. Compressor demand $\left(\mathrm{E}_{\mathrm{hp}}\right)$ and thermal output $\left(\mathrm{Q}_{1}\right)$ is modeled with a black box approach based on threedimensional interpolation of the source temperature, supply temperature, and compressor speed from a standard performance map (Madani et al., 2011). Heat extraction at the evaporator $\left(\mathrm{Q}_{2}\right)$ is calculated from $\mathrm{Q}_{1}-\mathrm{E}_{\mathrm{hp}}=\mathrm{Q}_{2}$. Compressor speed is managed with a PID controller (Type 23) based on a heating curve and the supply temperature. There is a $100 \mathrm{~kW}$ direct electric backup boiler for supporting the heat pump during peak loads and replacing it during faults. A fault happens when the inlet temperature from the boreholes falls below $-10{ }^{\circ} \mathrm{C}$. Additionally, each DHW tank has $18 \mathrm{~kW}$ backup heaters.

The baseline borehole field is sized using a modified ASHRAE method (Rolando et al., 2015) and has 12 x $300 \mathrm{~m}$ deep boreholes spaced $20 \mathrm{~m}$ apart with single U-tubes. Type 557a is used to model the field with boundary conditions based on typical Swedish granite absent water flow. The PVT collectors are based on a prototype design using a 280 W Perlight glass-glass PV module with an aluminum and copper heat exchanger fixed to the rear side. Modeling is done using Type 560 with validated boundary conditions (Sommerfeldt and Ollas, 2017). PV-only systems use the same model but without the PVT circulation pump activated. The PVT pump uses a dead-band controller between the outlet temperatures of the PVT collector and the boreholes (i.e. temperature difference at the heat exchanger). 


\section{$2.2 \mathrm{KPls}$ and System Boundaries}

The numerous components and approaches to solar heat pump system design makes uniform definitions for system performance difficult (Hadorn, 2015; Poppi et al., 2018). The primary perspective of this study is from the building owner, meaning the focus is on total heating system or building performance. SPF is defined using $\mathrm{SPF}_{4} \mathrm{from}$ Nordman et al. (2012) and modified to include the circulation pump for PVT, referred to here as SPF $4+$ and given in eq. 1 . In systems without PVT, the term $E_{p, p v t}$ is simply zero. No consideration for PV electricity supplying the heat pump is considered in the SPF definition. TLCC is described by eq. 2 and includes three major components: initial investment $(I)$, operations and maintenance $(O M)$, and residual value $(R V)$.

$$
\begin{aligned}
& S P F_{4+}=\frac{Q_{s h}+Q_{d h w}}{E_{h p}+E_{p, s r c}+E_{p, s n k}+E_{b b}+E_{b, d h w}+E_{p, p v t}} \\
& T L C C=I_{H P}+I_{B H}+I_{P V(T)}+O M_{S Y S}-R V_{P V(T)}-R V_{B H}
\end{aligned}
$$

The economic lifetime of the system is assumed 20 years to correspond with typical heat pump expectations. The OM costs are represented by eq. 3, which includes the purchase of electricity and maintenance of the solar and heat pump systems. A negative cost (i.e. revenue) is earned from the sale of PV overproduction to the grid. The PV and PVT systems are assumed to last 30 years and the boreholes 60 years, and therefore have a residual value that reduces the TLCC. The solar is represented by equation eq. 4 and is equivalent to the value of PV generation between years 21 to 30, and the residual borehole value uses the equivalent annual cost method shown in eq. 5 .

$$
\begin{aligned}
& O M_{S Y S}=\sum_{y=1}^{20} \frac{\left(E_{H P} \cdot\left[P_{e l, r} \cdot\left(1+r_{e l, r}\right)^{y}\right]\right)-\left(E_{p v, o p}+P_{e l, s}\right)+M_{H P}+M_{P V(T)}}{(1+d)^{y}} \\
& R V_{P V(T)}=\sum_{y=21}^{30} \frac{\left(E_{p v, s c}+\left[P_{e l, r} \cdot\left(1+r_{e l, r}\right)^{y}\right]\right)+\left(E_{p v, o p}+P_{e l, s}\right)-M_{P V(T)}}{(1+d)^{y}} \\
& R V_{B H}=\sum_{y=21}^{60} \frac{I_{B H}}{1-(1+d)^{60} / d} * \frac{1}{(1+d)^{y}}
\end{aligned}
$$

A table of critical economic values are given in Tab. 2. All prices are shown without VAT, however a $25 \%$ VAT is included in the results as it is an expected cost to the target building owner group. A government supplied $30 \%$ investment rebate is also applied to the PV and PVT systems. Costs and prices are originally in Swedish Kronor and converted to Euros using a 10:1 exchange rate. Retail electricity prices $\left(P_{e l, r}\right)$ are assumed to grow at $1 \%$ over the lifetime while wholesale $\left(P_{e l, s}\right)$ remains fixed, and all prices and discounting are in real terms.

Tab. 2: Economic boundary conditions and assumptions

\begin{tabular}{cccc}
\hline Symbol & Quantity & Value & Units \\
\hline$I_{H P}$ & Heat pump investment cost & 30,000 & $€$ \\
$I_{B H}$ & Borehole investment cost (Fixed) & 10,000 & $€$ \\
$I_{B H}$ & Borehole investment cost (Variable) & 29 & $€ / \mathrm{m}$ \\
$I_{P V}$ & PV investment cost & 1.2 & $€ / \mathrm{W}_{\mathrm{p}}$ \\
$I_{P V T}$ & PVT investment cost (Fixed) & 13,000 & $€$ \\
$I_{P V T}$ & PVT investment cost (Variable) & 800 & $€ /$ coll. \\
$P_{e l, r}$ & Retail electricity price & 0.12 & $€ / \mathrm{kWh}$ \\
$r_{e l, r}$ & Retail electricity price growth rate & 1 & $\% / \mathrm{year}$ \\
$P_{e l, s}$ & Wholesale (selling) electricity price & 0.03 & $€ / \mathrm{kWh}$ \\
$M_{H P}$ & Annual maintenance cost for HP & 600 & $€$ \\
$M_{P V}$ & Annual maintenance cost for PV & $1 \% \times I_{P V}$ & $€$ \\
$M_{P V T}$ & Annual maintenance cost for PVT & $2 \% \times I_{P V T}$ & $€$ \\
$d$ & Real discount rate & 3 & $\%$
\end{tabular}




\section{Results}

Results are presented in several stages that build on each other: first, there is a parametric analysis of the boreholes considering total length, spacing, and a combination of the two. Next, the minimum temperature in the borehole circuit is increased and one set of borehole patterns are rerun. Finally, one set of boreholes with the increased temperature limit are presented with reduced solar array sizes.

\subsection{Parametric Analysis for Boreholes}

The baseline borehole field has 12 holes at $300 \mathrm{~m}$ deep and $20 \mathrm{~m}$ apart. The length is reduced by removing two holes at each step and leaving the depth at $300 \mathrm{~m}$. Fig. 3 shows boreholes with as much as a $50 \%$ total length reduction with and without PVT over 20 years (note the y-axis starts at 2.4). In the baseline $3600 \mathrm{~m}$ case, the PVT has a negligible effect, lifting $\mathrm{SPF}_{4+}$ from 3.22 to 3.34 in year 20, a 3.7\% improvement. With a 50\% reduced length (1800 $\mathrm{m})$, the PVT improved $\mathrm{SPF}_{4+}$ from 2.79 to 3.00 in year 20 , a $7.5 \%$ improvement.

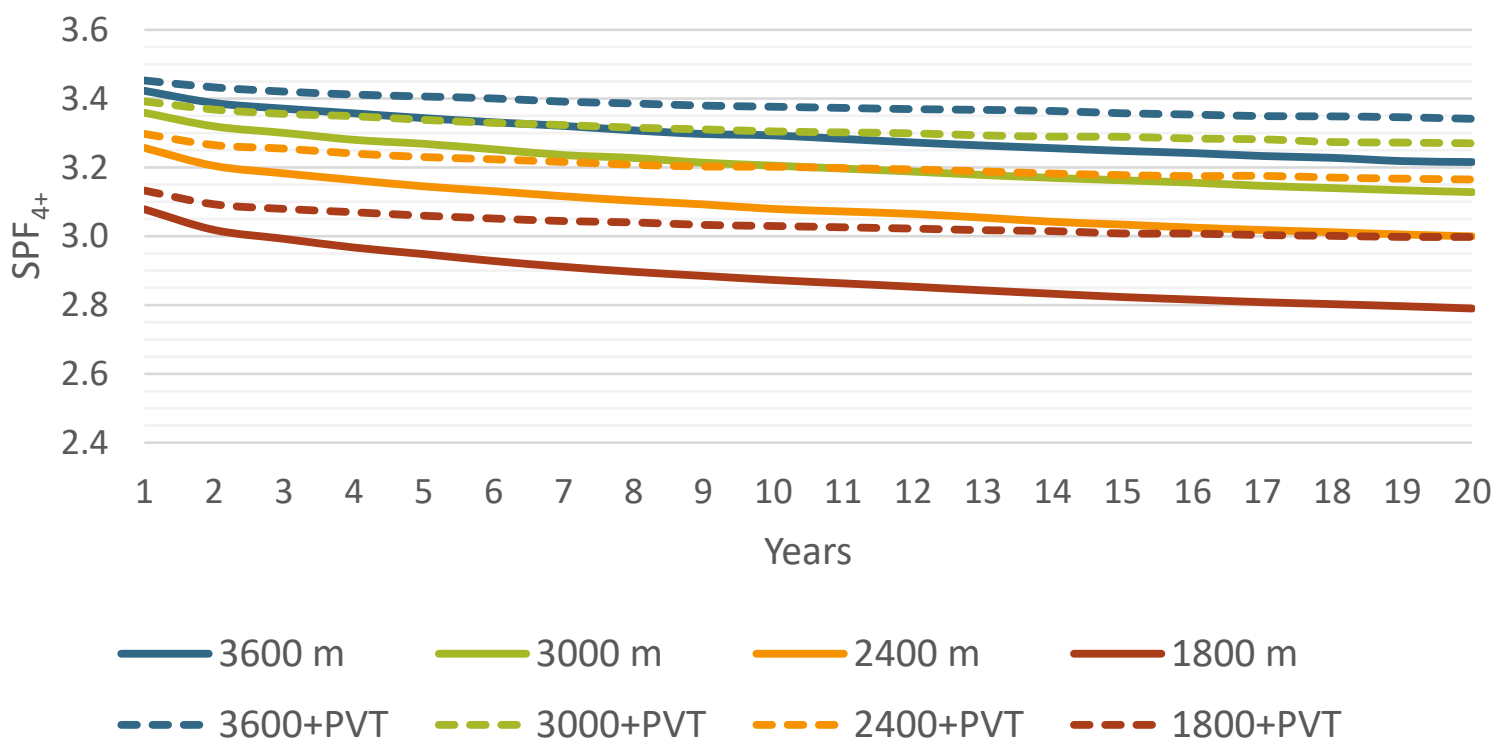

Fig. 3: $\mathrm{SPF}_{4+}$ over 20 years considering a reduced borehole length

When the borehole spacing is reduced, Fig. 4 shows that the impact of the PVT array is more pronounced. In the extreme 5 m case, PVT improves $\mathrm{SPF}_{4+}$ from 2.85 to 3.21 in year 20, which is a $13 \%$ improvement and the same performance as the $20 \mathrm{~m}$ baseline case. While the drilling costs would be similar due to the consistent length, the addition of PVT could significantly reduce the land area needed for a large GSHP system.



Fig. 4: $\mathrm{SPF}_{4+}$ over 20 years considering reduced borehole spacing 
To find a more extreme case, the borehole count and spacing are reduced together in combination cases. The legend in Fig. 5 shows the combinations without PVT in the top row, with total length as the first number and spacing as the second. The results with PVT are marked with code names for brevity. In comparison with the previous parametric results, $\mathrm{SPF}_{4+}$ is reduced by about $10-15 \%$. In the $1800 \times 5$ case, in year $20 \mathrm{SPF} 4+$ is 2.50 and becomes 2.91 when PVT is added, a $16 \%$ improvement.

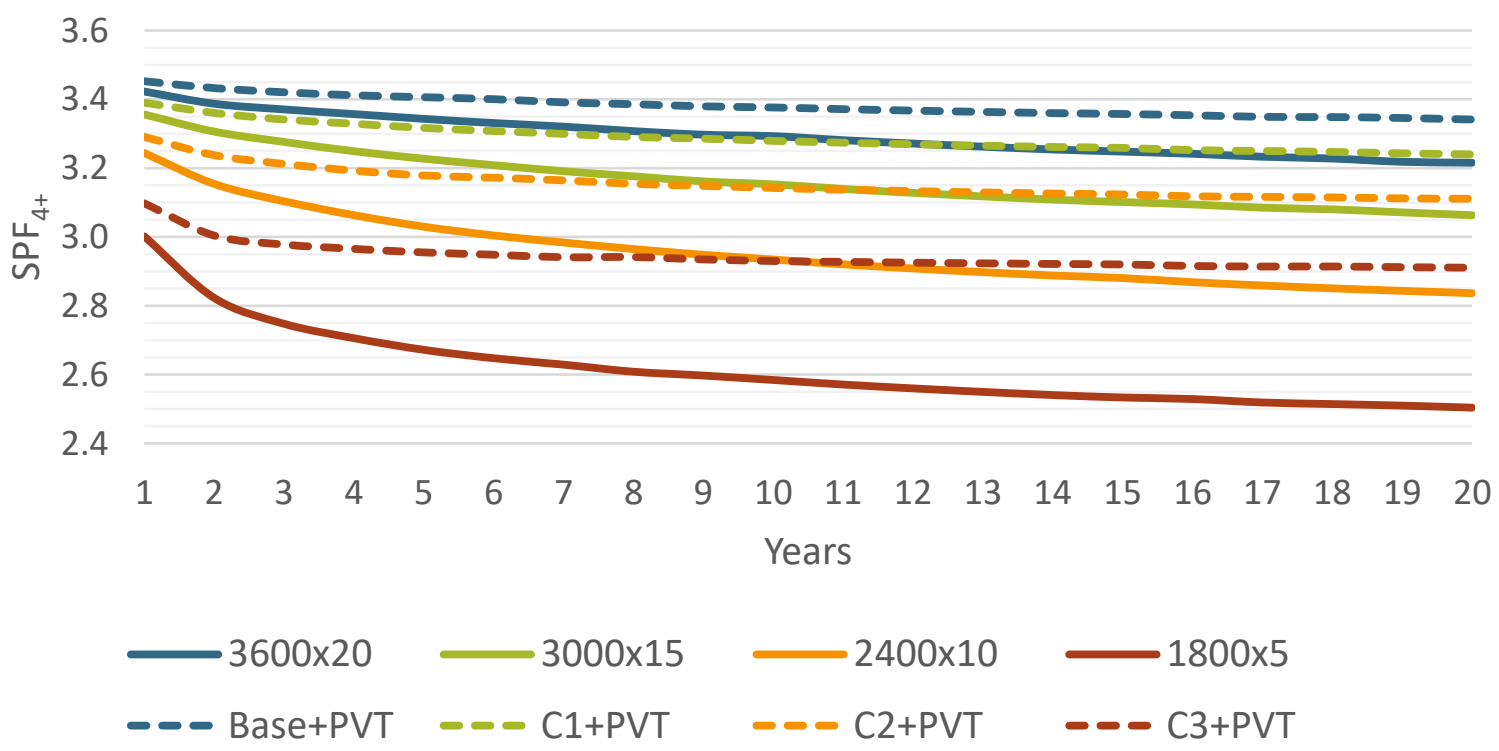

Fig. 5: $\mathrm{SPF}_{4+}$ over 20 years considering reduced borehole length and spacing

The performance of the undersized and compacted borehole fields, while low for a modern GSHP, are still surprisingly high. This is reflected in the TLCC, given in Fig. 6, where the lifecycle cost of GSHP are shown to be similar in all cases. The $1800 \times 5$ case is the highest due to the higher electricity consumption, but the cost savings of the boreholes makes up for most of it. In all cases, the PV array reduces energy costs, which is expected given the profitability of PV in Sweden (Sommerfeldt and Madani, 2017). However, PVT systems are 10-20\% more expensive than both PV and GSHP only systems, demonstrating that the electricity savings are not enough to justify a PVT investment.

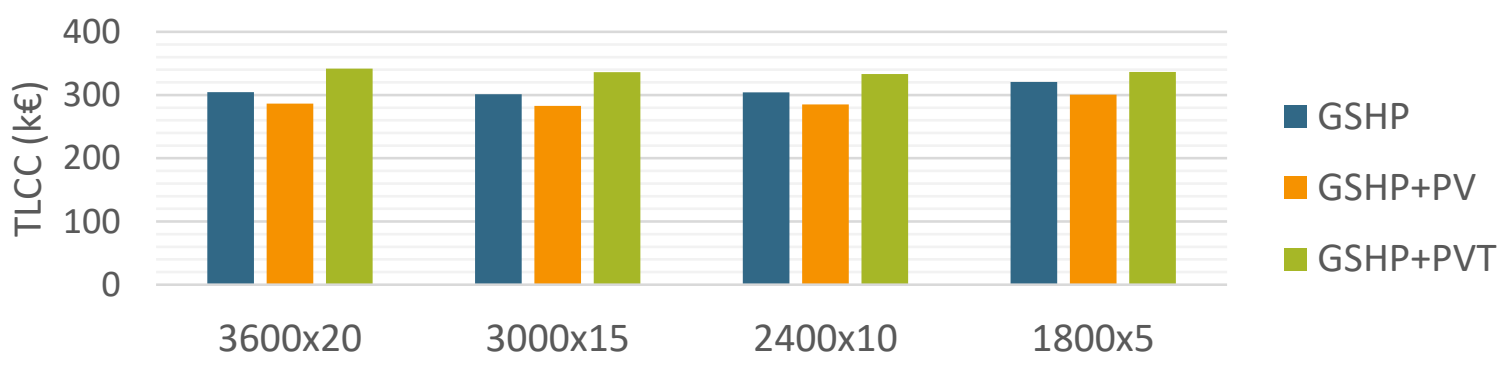

Fig. 6: TLCC for the combination borehole reduction cases

The results suggest an undersized borehole field and PV is the least cost option, however this is largely due to the operating range of the heat pump. Fig. 7 shows the monthly outlet fluid temperature from ground in the extreme 1800x $5 \mathrm{~m}$ case in Fig. 5. The solid lines represent the maximum and minimum while the dashed line is the average. Even without PVT, the minimum inlet temperature to the evaporator, $-10^{\circ} \mathrm{C}$, is never reached and thus the backup boiler is rarely used. However, the borehole temperature remains below freezing for the entire year, which could potentially damage the polyethylene pipes if liquid water inside the borehole froze and expanded. 




Fig. 7: Monthly minimum, maximum, and average borehole fluid outlet temperatures in the 1800x5 case with and without PVT

\subsection{Increased Minimum Borehole Temperature}

To test the impact borehole temperature limits have on performance, the combination borehole patterns in Fig. 5 are simulated with a $-4{ }^{\circ} \mathrm{C}$ minimum inlet temperature to the evaporator, which are given in Fig. 8 (note the change in scale on the y-axis). The results show a reduction in $\mathrm{SPF}_{4+}$ in the 2400x10 and 1800x5 cases, 1.70 and 2.53 in year 20 , respectively, due to frequent faults in the winter and increased direct electric boiler use. In the 1800x 5 case, the backup boiler is still needed even with the PVT array, but its electricity use is reduced by $80 \%$. The $\mathrm{SPF}_{4+}$ values for the $1800 \times 5$ case in year 20 with and without PVT are 1.70 and 2.70 , respectively, a $60 \%$ improvement.

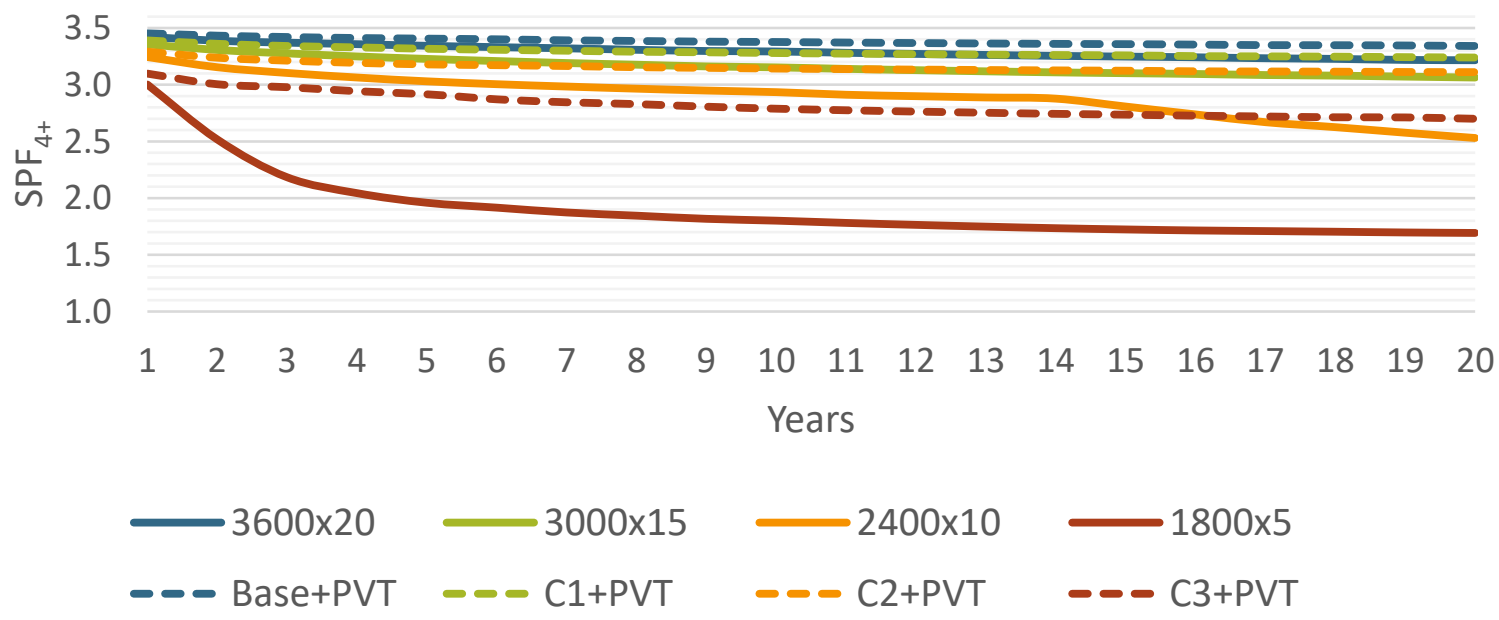

Fig. 8: $\mathrm{SPF}_{4+}$ of the combined borehole reductions with a $-4{ }^{\circ} \mathrm{C}$ minimum evaporator inlet temperature

A review of the borehole outlet temperatures with the $-4{ }^{\circ} \mathrm{C}$ limit, given in Fig. 9, shows how shutting down the heat pump keeps the borehole temperature higher. However even with this limit, without PVT the fluid temperature is below freezing most of the year, meaning the risk for damage is not entirely removed. With PVT, the fluid temperatures remain within an acceptable operating range, even in year 20 when they are showing signs of reaching steady state.

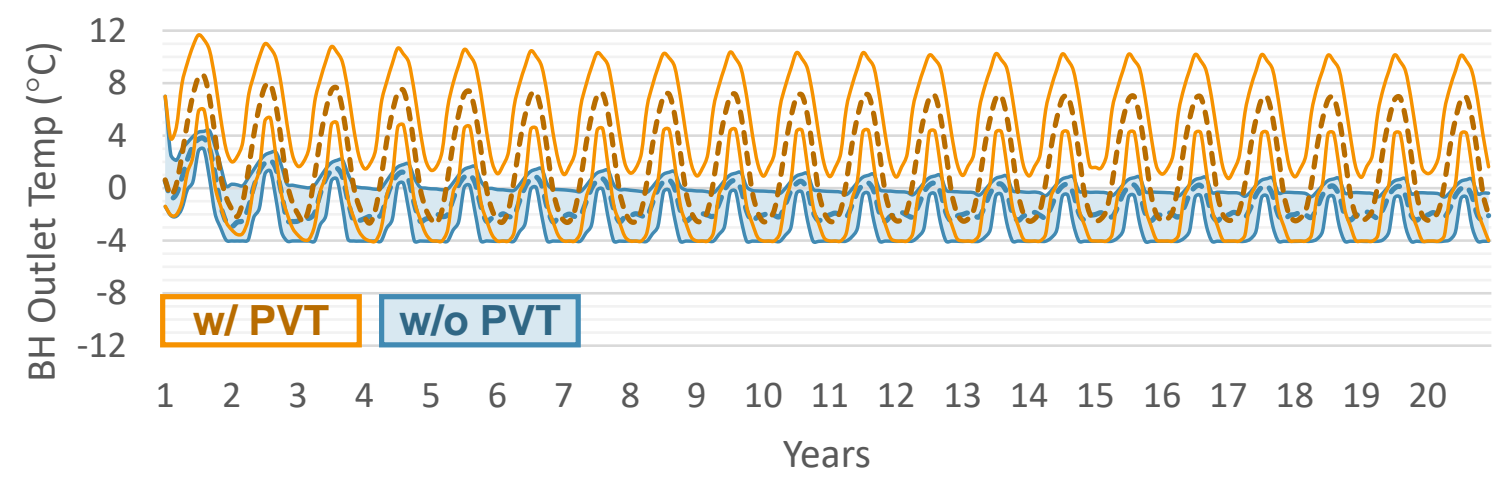

Fig. 9: Borehole fluid outlet temperatures of the $1800 \times 5$ case with a $-4{ }^{\circ} \mathrm{C}$ minimum evaporator inlet temperature 
The increased use of the backup boiler has a notable impact on $\mathrm{SPF}_{4+}$, which translates into a change in the economics. Fig. 10 shows the TLCC with the revised temperature limit, where it can be seen that there is now a case where PVT becomes the most economical option. In the 1800x5 case, PVT results in a savings of $70 \mathrm{k} €$, or $17 \%$. This is still a higher cost than any other borehole option in the study, suggesting that PVT is economically advantageous only in cases with high direct electric boiler usage with poor efficiency and a risk for borehole damage.

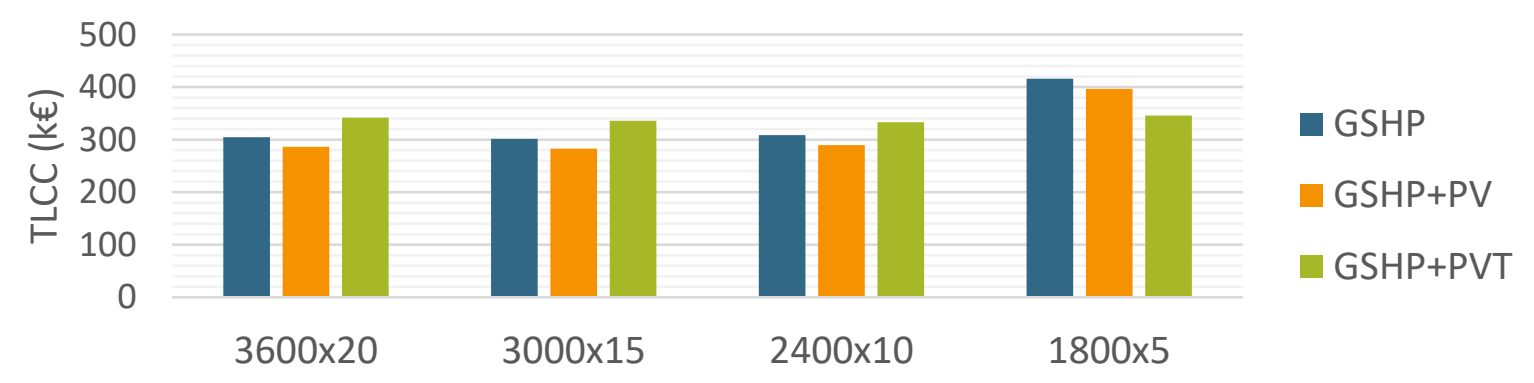

Fig. 10: TLCC for the combined borehole cases with a $-4^{\circ} \mathrm{C}$ minimum evaporator inlet temperature

\subsection{Parametric Analysis for Solar Arrays}

The building geometry and open roof space assumed in this study is atypical of many multi-family houses. Therefore, a reduction in solar collector area will indicate the potential for PVT+GSHP in a larger range of building types. The results shown in Fig. 11 are generated with the 1800x 5 borehole pattern and $-4{ }^{\circ} \mathrm{C}$ evaporator limit with PVT arrays from 144 down to 48 collectors $\left(79 \mathrm{~m}^{2}\right.$ and $13.4 \mathrm{~kW}_{\mathrm{p}}$ ). The addition of 48 collectors results in an $\mathrm{SPF}_{4+}$ improvement in year 20 from 1.70 to 2.09 , or $23 \%$. The improvement from additional collectors has diminishing returns but are can still be significant savings due to the low SPF values in consideration.



Fig. 11: $\mathrm{SPF}_{4+}$ for the $1800 \times 5$ / $-4^{\circ} \mathrm{C}$ case without and with PVT in several array sizes

In Fig. 12, the economic results show a similar pattern, where the addition of collectors has diminishing returns, however the full roof of 144 collectors has the lowest TLCC. This is due to the continued need for the auxiliary boiler even with the 144 collectors. In cases where the PVT can eliminate faults due to low-temperatures, the marginal costsavings will rapidly reduce and an optimal sizing point is likely to be found. This explanation comes by combining the results Fig. 12 and Fig. 6, and future study cases will be sought that can demonstrate this optimum directly.



Fig. 12: TLCC of the reduced solar array cases using the $1800 \times 5$ boreholes and $-4{ }^{\circ} \mathrm{C}$ evaporator limit 


\section{Discussion and Conclusions}

The cost reductions in PV has led to an increased interest in PVT technologies, particularly in combination with heat pumps. This study provides new information regarding the cost-effectiveness of a series connected PVT heat pump in multi-family buildings. The results show that the least cost and highest efficiency option is to install a full-sized borehole field with PV. PVT does enable a notable reduction in the land area required for a borehole field, which is often a challenge for multi-family houses in densely populated areas. For example, the area required in this study was reduced from $2400 \mathrm{~m}^{2}$ (3x4 pattern with $20 \mathrm{~m}$ spacing) to just $50 \mathrm{~m}^{2}$ ( $2 \times 3$ pattern with $5 \mathrm{~m}$ spacing) with a $13 \%$ increase in TLCC (ignoring the cost savings of land). In these cases, where the borehole length and/or spacing is restricted, PVT can be a cost-effective method to reduce auxiliary boiler usage and maintain higher ground temperatures, potentially opening new markets to GSHP.

Undersized boreholes can also occur in retrofit cases where a new, more efficient heat pump is installed to borehole(s) that have been cooled for two decades and are now expected to supply more heat. This is a growing problem in more mature heat pump markets, such as Sweden, where heat pumps have been used for many years. In cases with a potential for high boiler use, PVT could be a successful secondary heat source and will be explored in future work.

There are a considerable number of design options and variables in solar heat pump systems, both in configuration and control. This study presented a limited range of design choices that may be difficult to extend to other cases. A continuation of this work will include a broader parametric analysis with the goal of providing normalized results that are more widely applicable. Likewise, the economic results are limited to the Swedish market, where electricity and drilling prices are relatively low as compared to Europe. In markets with higher costs for drilling and/or electricity, then PVT+GSHP systems could become favorable. A decrease in PV and/or PVT costs could also change the results. A sensitivity analysis on these factors will also be included in future work.

The primary insight from this study is that series connect PVT+GSHP systems offer the most benefit to cases with undersized or constrained borehole fields. In markets where fossil fuels and/or district heating are the only options, PVT+GSHP offers a potential solution for reducing carbon emissions in large residential buildings in cold climates. It also has potential in retrofit markets for small or large applications and should be studied further to better describe the system behavior and benefits of the concept. Test site data is also needed for confirmation of the model results, and should be prioritized in future work.

\section{Acknowledgements}

This work is funded by the Swedish Energy Agency's Effsys Expand program (project number 40936-1) for which the authors are grateful.

\section{References}

Bertram, E., Glembin, J., Rockendorf, G., 2012. Unglazed PVT collectors as additional heat source in heat pump systems with borehole heat exchanger. Energy Procedia 30, 414-423. doi:10.1016/j.egypro.2012.11.049

Chapuis, S., Bernier, M., 2009. Seasonal storage of solar energy in borehole heat exchangers, in: Eleventh International IBPSA Conference. Glasgow, pp. 599-606.

Hadorn, J.-C. (Editor), 2015. Solar and Heat Pump Systems for Residential Buildings, First. ed. Ernst \& Sohn GmbH \& Co., Berlin.

Haller, M.Y., Frank, E., 2011. On the potential of using heat from solar thermal collectors for heat pump evaporators, in: ISES Solar World Congress. Kassel, Germany, pp. 1-10.

Hofmann, M., Riechelmann, S., Crisosto, C., Mubarak, R., Seckmeyer, G., 2014. Improved synthesis of global irradiance with one-minute resolution for PV system simulations. Int. J. Photoenergy 2014. doi:10.1155/2014/808509

Kjellsson, E., Hellström, G., Perers, B., 2010. Optimization of systems with the combination of ground-source heat pump and solar collectors in dwellings. Energy 35, 2667-2673. doi:10.1016/j.energy.2009.04.011

Klein, S., Beckman, W.A., Mitchell, J., Duffie, J.A., Freeman, T., 2009. TRNSYS 17, A Transient System Simulation Program.

Madani, H., Claesson, J., Lundqvist, P., 2011. Capacity control in ground source heat pump systems: Part I: Modeling and simulation. Int. J. Refrig. 34, 1338-1347. doi:10.1016/j.ijrefrig.2011.05.007

Nordman, R., Kleefkens, O., Riviere, P., Nowak, T., Zottl, A., Arzano-Daurelle, C., Lehmann, A., Polyzou, O., 
Karytsas, K., Riederer, P., Miara, M., Lindahl, M., Andersson, K., Olsson, M., 2012. SEasonal PErformance factor and MOnitoring for heat pump systems in the building sector SEPEMO-Build: FINAL REPORT.

Poppi, S., Sommerfeldt, N., Bales, C., Madani, H., Lundqvist, P., 2018. Techno-economic review of solar heat pump systems for residential heating applications. Renew. Sustain. Energy Rev. 81. doi:10.1016/j.rser.2017.07.041

Rad, F.M., Fung, A.S., 2016. Solar community heating and cooling system with borehole thermal energy storage Review of systems. Renew. Sustain. Energy Rev. 60, 1550-1561. doi:10.1016/j.rser.2016.03.025

Reda, F., 2015. Long term performance of different SAGSHP solutions for residential energy supply in Finland. Appl. Energy 144, 31-50. doi:10.1016/j.apenergy.2015.01.059

Remund, J., Kunz, S., 2018. Meteonorm 7.2.

Rolando, D., Acuna, J., Fossa, M., 2015. A Web Application for Geothermal Borefield Design. World Geotherm. Congr. 2015 19-25.

Sommerfeldt, N., Madani, H., 2017. Revisiting the techno-economic analysis process for building-mounted, gridconnected solar photovoltaic systems: Part two - Application. Renew. Sustain. Energy Rev. 74, 1394-1404. doi:10.1016/j.rser.2017.03.010

Sommerfeldt, N., Madani, H., 2016. Review of Solar PV/Thermal Plus Ground Source Heat Pump Systems for European Multi-Family Houses, in: 11th ISES Eurosun Conference. Palma de Mallorca, Spain.

Sommerfeldt, N., Ollas, P., 2017. Reverse Engineering Prototype Solar PV / Thermal Collector Properties from Empirical Data for Use in TRNSYS Type 560, in: Proc. of the ISES Solar World Congress 2017. ISES, Abu Dahbi.

Spets, K., 2012. TABULA Webtool [WWW Document]. URL http://webtool.building-typology.eu (accessed 5.31.15).

Widén, J., Lundh, M., Vassileva, I., Dahlquist, E., Ellegård, K., Wäckelgård, E., 2009. Constructing load profiles for household electricity and hot water from time-use data-Modelling approach and validation. Energy Build. 41, 753-768. doi:10.1016/j.enbuild.2009.02.013

Widén, J., Wäckelgård, E., 2010. A high-resolution stochastic model of domestic activity patterns and electricity demand. Appl. Energy 87, 1880-1892. doi:10.1016/j.apenergy.2009.11.006 